\title{
Analysis of the COVID-19 Pandemic: Lessons for a Contextualized and Effective Response to Public Health Emergencies
}

\section{Yibeltal Assefa ( $\square$ yibeltalassefa343@gmail.com )}

University of Queensland School of Public Health https://orcid.org/0000-0003-2393-1492

Charles F Gilks

The University of Queensland School of Public Health

Simon Reid

The University of Queensland School of Public Health

\section{Remco van de Pas}

Institute of Tropical Medicine: Instituut voor Tropische Geneeskunde

\section{Dereje Gedle Gete}

The University of Queensland School of Public Health

\section{Wim Van Damme}

Institute of Tropical Medicine: Instituut voor Tropische Geneeskunde

\section{Research}

Keywords: Pandemics, Epidemics, COVID-19, Heterogeneity, Governance, Equity

Posted Date: August 12th, 2021

DOl: https://doi.org/10.21203/rs.3.rs-779388/v1

License: (1) This work is licensed under a Creative Commons Attribution 4.0 International License. Read Full License 


\section{Abstract}

Background: The pandemic of Coronavirus Disease 2019 (COVID-19) is a timely reminder of the nature and impact of Public Health Emergencies of International Concern. As of 27 May 2021, there were over 169 million cases and over 3.5 million deaths notified since the start of the pandemic. The COVID-19 pandemic takes variable shapes and forms in different regions and countries of the world. The objective of this study is to analyse the COVID-19 pandemic so that lessons can be learned towards an effective public health emergency response.

Methods: We conducted a mixed-methods study to understand the heterogeneity of the COVID-19 pandemic. Correlation analysis and scatter plot were employed for the quantitative data. We used Spearman's correlation analysis. Thematic analysis was conducted on the qualitative data to explain the findings from the quantitative data.

Results: We have found that regions and countries with high human development index are most affected by COVID-19 due to international connectedness and mobility of their population related to trade and tourism, and their vulnerability related to older populations and higher rates of non-communicable diseases. The pattern of the pandemic is also variable among high- and middle-income countries due to differences in the governance of the pandemic, fragmentation of health systems, and socio-economic inequities.

Conclusion: The aspiration towards a healthier and safer society requires that countries develop and implement a coherent and context-specific national strategy, improve governance of public health emergencies, build the capacity of their (public) health systems, minimize fragmentation, and tackle upstream structural issues, including socio-economic inequities. This is possible through a primary health care approach, which ensures provision of universal and equitable promotive, preventive and curative services, through whole-of-government and whole-of-society approaches.

\section{Background}

The pandemic of Coronavirus Disease 2019 (COVID-19) is a timely reminder of the nature and impact of emerging infectious diseases that become Public Health Emergency of International Concern (PHEIC).[1] The COVID-19 pandemic takes variable shapes and forms in how it affects communities in different regions and countries.[2, 3] As of 27 May, 2021, there were over 169 million cases and over 3.5 million deaths notified since the start of the pandemic. The number of cases per million population ranged from 1,587 in Oceania to 66,751 in North America while the number of deaths per million population ranged from 29 in Oceania to 1,761 in South America. Case-fatality rates (CFRs) ranged from 1.3\% in Asia to $2.7 \%$ in South America. $[4,5]$ Regions and countries with high human development index (HDI), which is a composite index of life expectancy, education, and per capita income indicators,[6] are affected by COVID-19 more than regions with low HDI. North America and Europe together account for $51 \%$ and $56 \%$ 
of cases and deaths, respectively. Regions with high HDI are affected by COVID-19 despite their high universal health coverage index (UHCl) and Global Health Security index (GHSI).[7]

This seems to be a paradox in that the countries with higher $\mathrm{UHCl}$ and GHSI have experienced higher burdens of COVID-19.[7] The paradox can partially be explained by variations in testing algorithms, capacity for testing, and reporting across different countries. Countries with high HDI have health systems with a high testing capacity; the average testing rate per million population is less than 32,000 in Africa and 160,000 in Asia while it is more than 800, 000 in HICs (Europe and North America). This enables HICs to identify more confirmed cases that will ostensibly increase the number of reported cases. [3] Nevertheless, these are insufficient to explain the stark differences between countries with high HDI and those with low HDI. Many countries with high HDI have a high testing rate and a higher proportion of symptomatic and severe cases, which are also associated with higher deaths and CFRs.[7] On the other hand, there are countries with high HDI that sustain a lower level of the epidemic than others with a similar high HDI. It is, therefore, vital to analyse the heterogeneity of the COVID-19 pandemic and explain why some countries with high $\mathrm{HDI}, \mathrm{UHCl}$ and $\mathrm{GHSI}$ have the highest burden of COVID-19 while others are able to suppress their epidemics and mitigate its impacts.

The objective of this study was to analyse the COVID-19 pandemic and understand its variable expression with the intention to learn lessons for an effective and sustainable response to public health emergencies. We hypothesised that high levels of $\mathrm{HDI}, \mathrm{UHCl}$ and $\mathrm{GHSI}$ are essential but not sufficient for a healthier and safer world.

\section{Methods}

We conducted an explanatory mixed-methods study to understand and explain the heterogeneity of the pandemic around the world. The study integrated quantitative and qualitative secondary data. The following steps were included in the research process: (i) collecting and analysing quantitative epidemiological data, (ii) conducting literature review of qualitative secondary data and (iii) evaluating countries' pandemic responses to explain the variability in the COVID-19 epidemiological outcomes. The study then illuminated specific factors that were vital towards an effective and sustainable epidemic response.

We used the publicly available secondary data sources from Johns Hopkins University (https://coronavirus.jhu.edu/data/new-cases) for COVID-19 and UNDP 2020 HDI report (http://hdr.undp.org/en/2019-report) for HDI, demographic and epidemiologic variables. These data sources are regularly updated, open source and utilized by researchers, policy makers and funders. We performed a correlation analysis of the COVID-19 pandemic. We determined the association between COVID-19 cases, severity, deaths and CFRs at the 0.01 and 0.05 levels (2-tailed). We used Spearman's correlation analysis, as there is no normal distribution of the variables.[10]

The $\mathrm{UHCl}$ is calculated as the geometric mean of the coverage of essential services based on 17 tracer indicators from: (1) reproductive, maternal, newborn and child health; (2) infectious diseases; (3) non- 
communicable diseases; and, (4) service capacity and access and health security.[8] The GHSI is a composite measure to assess a country's capability to prevent, detect, and respond to epidemics and pandemics.[9]

We then conducted a document review to explain the epidemic patterns in different countries. Secondary data was obtained from peer-reviewed journals, reputable online news outlets, government reports and publications by public health-related associations, such as the WHO. To explain the variability of COVID19 across countries, a list of 14 indicators was established to systematically assess country's preparedness, actual pandemic response, and overall socioeconomic and demographic profile in the context of COVID-19. The indicators used in this study include: 1) Universal Health Coverage Index, 2) public health capacity, 3) Global Health Security Index, 4) International Health Regulation, 5) leadership, governance and coordination of response, 6) community mobilization and engagement, 7) communication, 8) testing, quarantines and social distancing, 9) medical services at primary health care facilities and hospitals, 10) multisectoral actions, 11) social protection services, 12) absolute and relative poverty status, 13) demography, and 14) burden of communicable and non-communicable diseases. We conducted thematic analysis and synthesis to identify the factors that may explain the heterogeneity of the pandemic.

\section{Results}

\section{Heterogeneity of COVID-19 cases and deaths around the world: What can explain it?}

Table 1 indicates that there is the pandemic of COVID-19 is heterogeneous around regions of the world. Figure 1 also shows that there is a strong and significant correlation between HDI and globalisation (with an increase in trade and tourism as proxy indicators) and a corresponding strong and significant correlation with COVID-19 burden. 
Table 1

COVID-19 cases, deaths and case-fatality rates in six regions of the world

\begin{tabular}{|lllllll|}
\hline Regions & $\begin{array}{l}\text { Cases per } \\
\text { mil pop }\end{array}$ & $\begin{array}{l}\text { Deaths per } \\
\text { mil pop }\end{array}$ & $\begin{array}{l}\text { Total } \\
\text { cases (\%) }\end{array}$ & $\begin{array}{l}\text { Total } \\
\text { deaths (\%) }\end{array}$ & $\begin{array}{l}\text { Tests per } \\
\text { mil pop }\end{array}$ & $\begin{array}{l}\text { Case-fatality } \\
\text { rate* }\end{array}$ \\
\hline $\begin{array}{l}\text { North } \\
\text { America }\end{array}$ & 66,751 & 1,497 & $23.4 \%$ & $25.3 \%$ & 897,725 & $2.2 \%$ \\
\hline Europe & 61,969 & 1,425 & $27.4 \%$ & $30.3 \%$ & $1,132,324$ & $2.3 \%$ \\
\hline $\begin{array}{l}\text { South } \\
\text { America }\end{array}$ & 64,876 & 1,761 & $16.6 \%$ & $21.8 \%$ & 267,969 & $2.7 \%$ \\
\hline Asia & 10,794 & 143 & $29.6 \%$ & $18.9 \%$ & 184,020 & $1.3 \%$ \\
\hline Africa & 3,528 & 95 & $2.9 \%$ & $3.7 \%$ & 34,841 & $2.7 \%$ \\
\hline Oceania & 1,587 & 29 & $0.1 \%$ & $0.0 \%$ & 479,488 & $1.8 \%$ \\
\hline World & $\mathbf{2 1 , 6 9 3}$ & $\mathbf{4 5 1}$ & $\mathbf{1 0 0 \%}$ & $\mathbf{1 0 0 \%}$ & $\mathbf{3 0 8 , 9 1 2}$ & $\mathbf{2 . 1 \%}$ \\
\hline Source: worldometer- COVID-19 coronavirus pandemic: https://www.worldometers.info/coronavirus/ \\
\hline *Case-fatality rate is calculated as a percentage of reported deaths out of reported cases of COVID-19 \\
\hline
\end{tabular}

Globalisation and pandemics interact in various ways, including through international trade and mobility, which can lead to multiple waves of infections.[11] In at least the first waves of the pandemic, countries with high import and export of consumer goods, food products and tourism have high number of cases, severe cases, deaths and CFRs. Countries with high HDI are at a higher risk of importing (and exporting) COVID-19 due to high mobility linked to trade and tourism, which are drivers of the economy. These led to multiple introductions of COVID-19 into these countries before border closures.

The COVID-19 pandemic was first identified in China, which is central to the global network of trade, from where it spread to all parts of the world, especially those countries with strong links with China.[12] The epidemic then spread to Europe. There is very strong regional dimension to manufacturing and trading, which could be facilitate the spread of the virus. China is the heart of 'Factory Asia'; Italy is in the heart of 'Factory Europe'; the United States is the heart of 'Factory North America'; and Brazil is the heart of 'Factory Latin America'.[13] These are the countries most affected by COVID-19 during the first wave of the pandemic. $[2,3,14]$

It is also important to note that two-third of the countries currently reporting more than a million cases are middle-income countries (MICs), which are not only major emerging market economies but also regional political powers, including the BRICS countries (Brazil, Russia, India and South Africa). $[3,15]$ These countries participate in the global economy, with business travellers and tourists. They also have decent domestic transportation networks that facilitate the internal spread of the virus. The strategies that helped these countries to become emerging markets also put them at greater risk for importing and spreading COVID-19 due to their connectivity to the rest of the world. 
In addition, countries with high HDI may be more significantly impacted by COVID-19 due to the higher age of the population and higher rates of non-communicable diseases. Figure 1 shows that there is a strong and significant correlation between HDI and demographic transition (high proportion of old-age population) and epidemiologic transition (high proportion of the population with non-communicable diseases). Countries with a higher proportion of people older than 65 years and NCDs (compared to communicable diseases) have higher burden of COVID-19.[16-20] Evidence has consistently shown a higher risk of severe COVID-19 in older individuals and those with underlying health conditions.[21-25] CFR is age-dependent; it is highest in persons aged $\geq 85$ years $(10-27 \%)$, followed by those among persons aged $65-84$ years $(3-11 \%)$, and those among persons aged $55-64$ years (1-3\%).[26]

On the other hand, regions and countries with low HDI have, to date, experienced less severe epidemics. For instance, as of May 27, 2021, the African region has recorded about 4.8 million cases and 129,000 deaths - far lower than other regions of the world (Table 1).[27] These might be due to lower testing rates in Africa, where only $3 \%$ of the population has been tested for the virus, $[14,28]$ and a greater proportion of infections may remain asymptomatic.[29] Indeed, the results from sero-surveys in Africa show that more than $80 \%$ of people infected with the virus were asymptomatic compared to an estimated $40 \%-50 \%$ asymptomatic infections in HICs.[30,31] Moreover, there is a weak vital registration system in the region indicating that the reports might be underestimated and inadequate.[32] However, does this fully explain the differences observed between Africa and Europe or the Americas?

Other possible factors that may explain the lower rates of cases and deaths in Africa include: (1) Africa is less internationally connected than other regions; (2) the imposition of early strict lockdowns in many African countries, at a time when case numbers were relatively small, further limited the number of imported cases; $[2,33,34](3)$ relatively poor road network has also limited the transmission of the virus to and in rural areas;[35] (4) a significant proportion of the population resides in rural areas and those in many urban areas spend a lot of their time mostly outdoors; (5) only about $3 \%$ of Africans are over the age of 65 (so only a small proportion are at risk of severe COVID-19);[36] (6) lower prevalence of NCDs, as disease burden in Africa comes from infectious causes, including coronaviruses, which may also have cross-immunity;[37] and (7) relative high temperature (a major source of vitamin D which influences COVID-19 infection and mortality) in the region may limit the spread of the virus.[38, 39] It is most likely that a combination of all these factors might explain the lower COVID-19 burden in Africa.

The early and timely efforts by African leaders should not be underestimated. The African Union, African $\mathrm{CDC}$, and WHO convened an emergency meeting of all African ministers of health to establish an African taskforce to develop and implement a coordinated continent-wide strategy focusing on: laboratory; surveillance; infection prevention and control; clinical treatment of people with severe COVID-19; risk communication; and supply chain management.[40] In April 2021, African Union and Africa CDC launched the Partnerships for African Vaccine Manufacturing (PAVM), framework to expanding Africa's vaccine manufacturing capacity for health security.[41] 


\section{Heterogeneity of the pandemic among countries with high HDI: What can explain it?}

Figures 2 and 3 illustrate the variability of COVID-19 pandemic across high-income countries (HICs). Contrary to the overall positive correlation between high HDI and the COVID-19 epidemic, there are outlier HICs, which have been able to control the epidemic. Several HICs, such as New Zealand, Australia, South Korea, Japan, Denmark, Iceland, and Norway, managed to contain their epidemics (Figs. 2 and 3).[15, 42, 43] It is important to note that most of these countries (especially the island states) have far less crossborder mobility than other HICs.

There are typical characteristics in HICs that have been able to limit their epidemics. These characteristics are related to governance (including integrity and trust) of the response,[44] synergy between UHC and GHS, and existing relative socio-economic equity in the country. Governance and leadership is a crucial factor to explain the heterogeneity of the epidemic among countries with high HDI.[45] There has been substantial variation in the nature and timing of the public health responses implemented.[46] Adaptable and agile governments seem better able to respond to their epidemics.[47, 48] Countries that have fared the best are the ones with good governance and public support.[49] Countries with an absence of coherent leadership and social trust have worse outcomes than countries with collective action, whether in a democracy or autocracy, and rapid mobilisation of resources.[50] The erosion of trust in the United States government has hurt the country's ability to respond to the COVID-19 crisis.[51, 52] The editors of the New England Journal of Medicine argued that the COVID-19 crisis has produced a test of leadership; but, the leaders in the United States had failed that test.[47]

COVID-19 has exposed the fragility of health systems, not only in the public health and primary care, but also in acute and long-term care systems.[49] Fragmentation of health systems, defined here to mean inadequate synergy and/ or integration between GHS and UHC, is typical of countries most affected by the COVID-19 pandemic. Even though GHS and UHC agendas are convergent and interdependent, they tend to have different policies and practices.[53] The United States has the highest index for GHS preparedness; however, it has reported the world's highest number of COVID-19 cases and deaths due to its greatly fragmented health system. $[54,55]$ Countries with health systems and policies that are able to integrate International Health Regulations (IHR) core capacities with primary health care (PHC) services have been effective at mitigating the effects of COVID-19.[50,53] Australia has been able to control its COVID-19 epidemic through a comprehensive primary care response (including protection of vulnerable people, provision of treatment and support services to affected people, continuity of regular healthcare services, protection and support of PHC workers and primary care services, and provision of mental health services to the community and the primary healthcare workforce).[56] Strict implementation of public health and social intervention together with UHC systems have ensured swift control of the epidemics in Singapore, South Korea, and Thailand.[57]

Socio-economic inequality is another factor that explains the variable burden of the pandemic. COVID-19 is understood to be more than a pandemic; it is indeed a syndemic, characterised by interactions that 
increase susceptibility to harm and/ or worsen health outcomes.[58] COVID-19 has been a stress test for public services and social protection systems, and many countries with high burden of COVID-19 have come up short. There is a higher burden of COVID-19 in Black, Asian and Minority Ethnic individuals due to socio-economic inequities. $[59,60]$ Poor people are more likely to live in overcrowded accommodation, are more likely to have unstable work conditions and incomes, have comorbidities associated with poverty and precarious living conditions, and reduced access to health care.[59]

The epidemiology of COVID-19 is also variable across MICs, with HDI between 0.70 and 0.85 , around the world. Overall, the epidemic in MICs is exacerbated by the rapid demographic and epidemiologic transitions as well as high prevalence of obesity. While India and Brazil witnessed rapidly increasing rates of cases and deaths, China, Thailand, Vietnam have experienced a relatively lower disease burden.[15] This heterogeneity may be attributed to a number of factors, including governance, communication and service delivery. Thailand, China and Vietnam have implemented a national harmonized strategic response with decentralized implementation through provincial and district authorities.[61] Thailand increased its testing capacity from two to over 200 certified facilities that could process between 10,000 to 100,000 tests per day; moreover, over a million village health volunteers in Thailand supported primary health services. $[62,63]$ China's swift and decisive actions enabled the country to contain its epidemic though there was an initial delay in detecting the disease. China has been able to contain its epidemic through community-based measures, very high public cooperation and social mobilization, strategic lockdown and isolation, multi-sector action.[64] Overall, multi-level governance (effective and decisive leadership and accountability) of the response, together with synergies between public health and socioeconomic interventions, and high levels of citizen adherence to personal protection, have enabled these countries to successfully contain their epidemics.[61, 65, 66]

On the other hand, the Brazilian leadership was denounced for its failure to establish a national surveillance network early in the pandemic. In March 2020, the health minister was reported to have stated that mass testing was a waste of public funding, and to have advised against it.[67] This was considered as an indicator of a collapse of public health leadership, characterized by ignorance, neoliberal authoritarianism.[68] There were also gaps in the public health capacity in different municipalities, which varied greatly, with a considerable number of Brazilian regions receiving less funding from the federal government due to political tension.[69] The epidemic has a disproportionate adverse burden on states and municipalities with high socio-economic vulnerability, exacerbated by the deep social and economic inequalities in Brazil.[70]

India is another middle-income country with a high burden of COVID-19. It was one of the countries to institute strict measures in the early phase of the pandemic.[71, 72] However, the government eased restrictions after the claim that India had beaten the pandemic, which lead to a rapid increase in disease incidence. Indeed, on 12 May 2021, India reported 343, 288 new cases bringing the total cases to 24 million with almost 4,000 deaths.[15] The second wave of the epidemic in India exposed weaknesses in governance and inadequacies in the country's health and other social systems.[73] The nature of the Indian federation, which is highly centripetal, has prevented state and local governments from tailoring a 
policy response to suit local needs. A centralized one-size-fits-all strategy has been imposed despite high variations in resources, health systems capacity, and COVID-19 epidemics across states.[74] There were also lax social distancing and mask wearing, mass political rallies and religious events.[75] Rapid community transmission driven by high population density and multigenerational households has been a feature of the current wave in India.[76] In addition, several new variants of the virus, including the UK (B.1.1.7), the South Africa (20H/501Y or B.1.351), and Brazil (P.1), alongside a newly identified Indian variant (B.1.617), are circulating in India and have been implicated as a factor in the second wave of the pandemic.[75, 76]

\section{Heterogeneity of case-fatality rates around the world: What can explain it?}

The pandemic is characterized by variable CFRs across regions and countries that are negatively associated with HDI (Fig. 1). What factors can then explain the heterogeneity of CFRs around the world? The results presented in Fig. 4 show that the proportion of elderly population and rate of obesity are important factors which are positively associated with CFR. On the other hand, UHC, IHR capacity and other indicators of health systems capacity (health workforce density and hospital beds) are negatively associated with the CFR (Figs. 1 and 4).

The evidence from several research indicate that heterogeneity can be explained by several reasons, including differences in age-pyramid, socio-economic status, access to health services, or rates of undiagnosed infections. Differences in age structure may explain some of the observed variation in epidemic severity and CFR between countries.[77] CFRs across countries look similar when taking age into account.[78] The elderly and other vulnerable populations in Africa and Asia are at a similar risk as populations in Europe and Americas.[79] Data from European countries suggest that as high as $57 \%$ of all deaths have happened in care homes and many deaths in the US have also occurred in nursing home. On the other hand, in countries such as Mexico and India, individuals $<65$ years contributed the majority. [80] Failure to recognize infections in younger populations and milder cases diminishes the denominator in CFR calculations.

Nevertheless, CFR also depends on the quality of hospital care, which can be used to judge the health system capacity, including the availability of healthcare workers, resources, and facilities, which affects outcomes.[81] The CFR can increase if there is a surge of infected patients, which adds to the strain on the health system.[82] COVID-19 fatality rates are affected by numerous health systems factors, including intensive care unit (ICU), hospital bed capacity, and critical care resources (such as oxygen and dexamethasone). Regions and countries with high HDI have a greater number of acute care facilities, ICU, and hospital bed capacities compared to lower HDI regions and countries.[83] Differences in health systems capacity could explain why North America and Europe, which have experienced much greater number of cases and deaths per million population, reported lower CFRs than the Southern American and the African regions, partly also due to limited testing capacity in these regions (Table 1).[84-86] The higher CFR in Southern America can be explained by the relatively lower health systems and surge 
capacity that could not adequately respond to the huge demand for health services.[69, 86] The COVID-19 pandemic has highlighted existing weaknesses in health systems, which are not able to effectively prepare for and respond to PHEs.[87] The high CFRs in the region are also exacerbated by the high social inequalities and informal employment.[69]

On the other hand, countries in Asia recorded lower CFRs ( 1.4\%) despite sharing many common risk factors (including overcrowding and poverty, weak health system capacity etc). The Asian region shares many similar protective factors to the African region. They have been able to minimize their CFR by suppressing the transmission of the virus and flattening the curve. Nevertheless, the current wave in India is likely to be different because it has exceeded the health system capacity to respond and provide basic medical care and medical supplies such as oxygen.[88] Overall, many Asian countries were able to withstand the transmission of the virus and its effect due to swift action by governments in the early days of the pandemic despite the frequency of travel between China and neighbouring countries such as Hong Kong, Taiwan and Singapore.[89] This has helped them to contain the pandemic to ensure case numbers remain within their health systems capacity. These countries have benefited from their experience in the past in the prevention and control of epidemics.[90]

There are a number of issues with the use of the CFR to compare the management of the pandemic between countries and regions,[91] as it does not depict the true picture of the mortality burden of the pandemic. A major challenge with accurate calculation of the CFR is the denominator. Asymptomatic infections and patients with mild symptoms are frequently left untested, and therefore omitted from CFR calculations. Testing might not be widely available, and proactive contact tracing and containment might not be employed, resulting in a smaller denominator, and skewing to a higher CFR.[82] It is, therefore, far more relevant to estimate infection fatality rate (IFR), the proportion of all infected individuals who have died due to the infection,[91] which is central to understanding the public health impact of the pandemic and the required policies for its prevention and control.[92]

Estimates of prevalence based on sero-surveys, which includes asymptomatic and mildly symptomatic infections, can be used to estimate IFR.[93] In a systematic review of 17 studies, seroprevalence rates ranged from $0.22 \%$ in Brazil to $53 \%$ in Argentina.[94] The review also identified that the seroprevalence estimate was higher than the cumulative reported case incidence, by a factor between 1.5 times in Germany to 717 times in Iran, in all but two studies (0.56 times in Brazil and 0.88 times in Denmark).[94, 95] The difference between seroprevalence and cumulative reported cases might be due to asymptomatic cases, atypical or pauci-symptomatic cases, or the lack of access to and uptake of testing.[94] There is only a modest gap between the estimated number of infections from seroprevalence surveys and the cumulative reported cases in regions with relatively thorough symptom-based testing. Much of the gap between reported cases and seroprevalence is likely to be due to undiagnosed symptomatic or asymptomatic infections.[94]

\section{Discussion}


This study identifies that the COVID-19 pandemic is heterogeneous around the world due to differences in vulnerability, preparedness, and response. It confirms that a high level of $\mathrm{HDI}, \mathrm{UHCl}$ and GHSI are essential but not sufficient to control epidemics.[96] An effective response to public health emergencies requires a joint and reinforcing implementation of $\mathrm{UHC}$, health emergency and disease control priorities, $[97,98]$ as well as good governance and social protection systems.[99] Strategies to cope better with the COVID-19 pandemic and future emerging or re-emerging pandemics should strengthen health systems, minimize fragmentation of public health, primary care and secondary care, and improve coordination with other sectors according to the "health-in- all-policies' approach.[100] The pandemic has exposed the health effects of longstanding social inequities, which should be addressed through policies and actions to tackle vulnerability in living and working conditions.[99]

On the other hand, the pandemic has significant collateral effects on the provision of essential health services, in addition to the direct health effects.[101] Disruptions in the provision of essential health services due to COVID-19 were reported by nearly all countries, though it is more so in lower-income than higher-income countries.[102, 103] The biggest impact reported is on provision of day-to-day primary care to prevent and manage some of the most common health problems.[104] The causes of the disruptions were a mix of demand and supply factors.[105] Countries reported that just over one-third of services were disrupted due to health workforce-related reasons (the most common causes of service disruptions), supply chains, community mistrust and fears of becoming infected, and financial challenges.[106] Cognizant of the disruptive effects of the pandemic, countries have reorganized their health system. Countries with better response to COVID-19 have mobilized, trained and reallocated their health workforce in addition to hiring new staff, using volunteers and medical trainees and mobilizing retirees.[107] Several strategies have also been implemented to mitigate disruptions in service delivery and utilization, including: triaging to identify the most urgent patient needs, and postponing elective medical procedures; switching to alternative models of care, such as providing more home-based care and telemedicine.[106]

The shift in the pandemic epicentre from high-income to MICs is observed in the second global wave of the pandemic. This is due to in part to the large-scale provision of vaccines in HICs[15] as well as the limitations in the response in LMICs, including inadequate testing, quarantine and isolation, contact tracing, and social distancing. The second wave of the pandemic in low- and middle-income countries has spread more rapidly than the first wave and affected younger and healthier populations due to factors, including poor government decision making, citizen behaviour, and the emergence of highly transmissible SARS-CoV-2 variants.[108] It has become catastrophic in some MICs to prematurely relax key public health measures, such as mask wearing, physical distancing, and hand hygiene.[109]

There is consensus that global vaccination is essential to ending the pandemic. Universal and equitable vaccine delivery, implemented with high volume, speed and quality, is vital for an effective and sustainable response to the current pandemic and future public health emergencies. There is, however, ongoing concern regarding access to COVID-19 vaccines in resource-limited countries.[110] Moreover, there is shortage of essential supplies, including oxygen, which has had a major impact on the prevention and control of the pandemic. It is, therefore, vital to transform (through good governance and financing 
mechanisms) the ACT-A platform to deliver vaccines, therapeutics, diagnostics, and other essential supplies. $[110,111]$ The global health community has the responsibility to address these inequalities so that we can collectively end the pandemic.[108]

Overall, the COVID-19 pandemic and the response to it highlight valuable lessons towards an effective and sustainable response to public health emergencies. We argue that the PHC approach captures the different preparedness and response strategies required towards ensuring health security and UHC.[112] The PHC approach enables countries to progressively realize universal access to good-quality health services (including essential public health functions) and equity, empower people and communities, strengthen multi-sectoral policy and action for health, and enhance good governance.[113] These are essential in the prevention and control of public health emergencies, to suppress transmission, and reduce morbidity and mortality.[114] Access to high-quality primary care is at the foundation of any strong health system,[115] which will, in turn, have effect on containing the epidemic, and reducing mortality and CFR.[116] Australia is a good example in this regard because it has implemented a comprehensive PHC approach (including protection of vulnerable people, continuity of regular PHC services, and protection and support of $\mathrm{PHC}$ workers) in combination with border restrictions to ensure health system capacity is not exceeded.[56] The PHC approach will enable countries to develop and implement a context-specific health strategy, enhance governance, strengthen their (public) health systems, minimize segmentation and fragmentation, and tackle upstream structural issues, including discrimination and socio-economic inequities.[117] This is the type of public health approach (comprehensive, equity-focused and participatory) that will be effective and sustainable to tackle public health emergencies in the 21st century.[118] In addition, it is vital to transform the global and regional health systems, with a strong IHR and an empowered WHO at the apex.[119] We contend that this is the way towards a healthier and safer country, region and world.

\section{Conclusion}

The COVID-19 pandemic demonstrates that the world remains vulnerable to public health emergencies with significant health and other socio-economic impacts. The pandemic takes variable shapes and forms across regions and countries around the world. The pandemic has impacted countries with inadequate governance of the epidemic, fragmentation of their health systems and higher socioeconomic inequities more than others. We argue that adequate response to public health emergencies requires that countries develop and implement a context-specific national strategy, enhance governance of public health emergency, build the capacity of their health systems, minimize fragmentation, and tackle socio-economic inequities. This is possible through a PHC approach that provides universal access to good-quality health services through empowered communities and multi-sectoral policy and action for health development. The pandemic has affected every corner of the world; it has demonstrated that "no country is safe unless other countries are safe". This should be a call for a strong global health system based on the values of justice and capabilities for health. 


\section{Abbreviations}

COVID-19: Coronavirus Disease 2019

CFRs: Case-fatality rates

HDI: human development index

UHCl: universal health coverage index

GHSI: Global Health Security index

HICs: High-income countries

MICs: Middle-income countries

\section{Declarations}

Ethics approval and consent to participate: Not applicable.

Consent for publication: Not applicable.

Availability of data and materials: Data are available in a public, open access repository: Johns Hopkins University: https://coronavirus.jhu.edu/data/new-cases, and UNDP: http://hdr.undp.org/en/2019report; WHO: https://www.who.int/publications/m/item/weekly-epidemiological-update--22-december2020

Competing interests: None.

Funding: No funding was obtained for this study.

Authors' Contributions: YA conceived the idea of the research, collected and analysed the data, and prepared the first and subsequent drafts. DG participated in data collection and analysis. CFG, SR, RVDP, DG and WVD provided comments during subsequent drafts.

Acknowledgements: Not applicable.

\section{References}

1. El Zowalaty ME, Järhult JD. From SARS to COVID-19: A previously unknown SARS-CoV-2 virus of pandemic potential infecting humans-Call for a One Health approach. One health (Amsterdam, Netherlands) 2020:100124.

2. Van Damme W, Dahake R, Delamou A, Ingelbeen B, Wouters E, Vanham G, van de Pas R, Dossou J-P, Ir P, Abimbola S. The COVID-19 pandemic: diverse contexts; different epidemics-how and why? BMJ global health. 2020;5(7):e003098.

3. World Health Organization (WHO). Coronavirus disease ( COVID-19): situation report, 150. 2020.

4. Weekly epidemiological update - 22 December 2020 https://www.who.int/publications/m/item/weekly-epidemiological-update-22-december-2020. 
5. Worldometer: COVID-19 Coronavirus Pandemic. In., vol. 2020; 2020.

6. Anand S, Sen A: Human Development Index: Methodology and Measurement. 1994.

7. De Larochelambert Q, Marc A, Antero J, Le Bourg E, Toussaint J-F. Covid-19 mortality: a matter of vulnerability among nations facing limited margins of adaptation. Frontiers in Public Health 2020, 8.

8. Universal. health coverage [http://www.who.int/universal_health_coverage/en/ ].

9. Global Health Security Index [https://.

10. de Winter JC, Gosling SD, Potter J. Comparing the Pearson and Spearman correlation coefficients across distributions and sample sizes: A tutorial using simulations and empirical data. Psychol Methods. 2016;21(3):273.

11. Pol Antràs SJR, Esteban Rossi-Hansberg: How do globalisation and pandemics interact? Surprising insights from a new model. In: \#LSEThinks / CEP / Global development vol. 2020. London: London School of Economics; 2020.

12. Cai P: Understanding China's belt and road initiative. 2017.

13. Baldwin R, Tomiura E. Thinking ahead about the trade impact of COVID-19. Economics in the Time of COVID-192020, 59.

14. Organization WH: Coronavirus disease ( COVID-19): situation report, 182. 2020.

15. Johns Hopkins University. COVID-19 Map - Johns Hopkins Coronavirus Resource Center. In. Edited by Security JHUCfH; 2021.

16. Wang T, Du Z, Zhu F, Cao Z, An Y, Gao Y, Jiang B. Comorbidities and multi-organ injuries in the treatment of COVID-19. The Lancet. 2020;395(10228):e52.

17. Wang D, Hu B, Hu C, Zhu F, Liu X, Zhang J, Wang B, Xiang H, Cheng Z, Xiong Y. Clinical characteristics of 138 hospitalized patients with 2019 novel coronavirus-infected pneumonia in Wuhan, China. Jama. 2020;323(11):1061-9.

18. Huang C, Wang Y, Li X, Ren L, Zhao J, Hu Y, Zhang L, Fan G, Xu J, Gu X. Clinical features of patients infected with 2019 novel coronavirus in Wuhan, China. The lancet. 2020;395(10223):497-506.

19. Chen N, Zhou M, Dong X, Qu J, Gong F, Han Y, Qiu Y, Wang J, Liu Y, Wei Y. Epidemiological and clinical characteristics of 99 cases of 2019 novel coronavirus pneumonia in Wuhan, China: a descriptive study. The Lancet. 2020;395(10223):507-13.

20. Hussain A, Bhowmik B, do Vale Moreira NC: COVID-19 and diabetes: Knowledge in progress. Diabetes research and clinical practice 2020:108142.

21. Covid C, COVID C, COVID C, Chow N, Fleming-Dutra K, Gierke R, Hall A, Hughes M, Pilishvili T, Ritchey $M$ : Preliminary estimates of the prevalence of selected underlying health conditions among patients with coronavirus disease 2019-United States, February 12-March 28, 2020. Morbidity and Mortality Weekly Report 2020, 69(13):382.

22. Group C-S: Characteristics of COVID-19 patients dying in Italy: report based on available data on March 20th, 2020. Rome, Italy: Instituto Superiore Di Sanita; 2020. In. 
23. Guan W-j, Ni Z-y, Hu Y, Liang W-h, Ou C-q, He J-x, Liu L, Shan H. Lei C-I, Hui DS: Clinical characteristics of coronavirus disease 2019 in China. New England journal of medicine. 2020;382(18):1708-20.

24. Arentz M, Yim E, Klaff L, Lokhandwala S, Riedo FX, Chong M, Lee M. Characteristics and outcomes of 21 critically ill patients with COVID-19 in Washington State. Jama. 2020;323(16):1612-4.

25. Richardson S, Hirsch JS, Narasimhan M, Crawford JM, McGinn T, Davidson KW, Barnaby DP, Becker LB, Chelico JD, Cohen SL: Presenting characteristics, comorbidities, and outcomes among $\mathbf{5 7 0 0}$ patients hospitalized with COVID-19 in the New York City area. Jama 2020.

26. Covid C, Team R. Severe outcomes among patients with coronavirus disease 2019 (COVID-19)United States, February 12-March 16, 2020. MMWR Morb Mortal Wkly Rep. 2020;69(12):343-6.

27. Mbow M, Lell B, Jochems SP, Cisse B, Mboup S, Dewals BG, Jaye A, Dieye A, Yazdanbakhsh M: COVID-19 in Africa: Dampening the storm? Science 2020, 369(6504):624-626.

28. Kavanagh MM, Erondu NA, Tomori O, Dzau VJ, Okiro EA, Maleche A, Aniebo IC, Rugege U, Holmes CB, Gostin LO. Access to lifesaving medical resources for African countries: COVID-19 testing and response, ethics, and politics. The Lancet. 2020;395(10238):1735-8.

29. Nordling L. Africa's pandemic puzzle: why so few cases and deaths? In. American Association for the Advancement of Science; 2020.

30. Oran DP, Topol EJ: Prevalence of Asymptomatic SARS-CoV-2 Infection: A Narrative Review. Annals of Internal Medicine 2020.

31. Nikolai LA, Meyer CG, Kremsner PG, Velavan TP. Asymptomatic SARS Coronavirus 2 infection: Invisible yet invincible. International Journal of Infectious Diseases 2020.

32. Rao C, Bradshaw D, Mathers CD. Improving death registration and statistics in developing countries: Lessons from sub-Saharan Africa. Southern African Journal of Demography 2004:81-99.

33. Mehtar S, Preiser W, Lakhe NA, Bousso A, TamFum J-JM, Kallay O, Seydi M, Zumla A, Nachega JB. Limiting the spread of COVID-19 in Africa: one size mitigation strategies do not fit all countries. The Lancet Global Health 2020.

34. Nachega J, Seydi M, Zumla A. The Late arrival of coronavirus disease 2019 (COVID-19) in Africa: Mitigating pan-continental spread. Clin Infect Dis. 2020;71(15):875-8.

35. Gwilliam K, Foster V, Archondo-Callao R, Briceno-Garmendia C, Nogales A, Sethi K. Africa infrastructure country diagnostic: roads in Sub-Saharan Africa. In.: The World Bank; 2008.

36. Guengant J-P. Africa's population: history, current status, and projections. In: Africa's Population: In Search of a Demographic Dividend. edn.: Springer; 2017. pp. 11-31.

37. Collaborators GOD, Bernabe E, Marcenes W, Hernandez C, Bailey J, Abreu L, Alipour V, Amini S, Arabloo J, Arefi Z. Global, regional, and national levels and trends in burden of oral conditions from 1990 to 2017: a systematic analysis for the global burden of disease 2017 study. Journal of dental research. 2020;99(4):362-73.

38. Cambaza EM, Viegas GC, Cambaza C, Manuel a. Potential impact of temperature and atmospheric pressure on the number of cases of COVID-19 in Mozambique, Southern Africa. Journal of Public 
Health Epidemiology. 2020;12(3):246-60.

39. Lawal Y. Africa's low COVID-19 mortality rate: A paradox? International journal of infectious diseases. 2021;102:118-22.

40. Nkengasong JN, Mankoula W. Looming threat of COVID-19 infection in Africa: act collectively, and fast. The Lancet. 2020;395(10227):841-2.

41. African Union, Africa CDC. African Union and Africa CDC launches Partnerships for African Vaccine Manufacturing (PAVM), framework to achieve it and signs 2 MoUs. In.: African Union and Africa CDC; 2021.

42. What Do Countries With The Best Coronavirus Responses Have In Common? Women Leaders [https://.

43. What can we learn from Austria's response to COVID-19? https://keough.nd.edu/what-can-we-learnfrom-austrias-response-to-covid-19/.

44. Stoller JK. Reflections on leadership in the time of COVID-19. BMJ Leader 2020.

45. What. 6 Of The 7 Countries With The Most COVID-19 Cases Have In Common https://www.npr.org/sections/goatsandsoda/2020/07/31/896879448/the-nations-with-the-most-tolose-from-covid-19.

46. Hale T, Petherick A, Phillips T, Webster S: Variation in government responses to COVID-19. Blavatnik school of government working paper 2020, 31.

47. Dying in a Leadership Vacuum. New England Journal of Medicine 2020, 383(15):1479-1480.

48. US and UK are bottom of the pile in rankings of governments' handling of coronavirus pandemic https://edition.cnn.com/2020/08/27/world/global-coronavirus-attitudes-pew-intl/index.html.

49. Huston P, Campbell J, Russell G, Goodyear-Smith F, Phillips RL, van Weel C, Hogg W. COVID-19 and primary care in six countries. BJGP open 2020, 4(4).

50. Goodyear-Smith F, Kinder K, Eden AR, Strydom S, Bazemore A, Phillips R, Taylor M, George J, Mannie C. Primary care perspectives on pandemic politics. Global Public Health 2021:1-16.

51. Rutledge PE. Trump, COVID-19, and the War on Expertise. The American Review of Public Administration. 2020;50(6-7):505-11.

52. Ugarte DA, Cumberland WG, Flores L, Young SD. Public attitudes about COVID-19 in response to president trump's social media posts. JAMA Network Open. 2021;4(2):e210101-1.

53. Lal A, Erondu NA, Heymann DL, Gitahi G, Yates R. Fragmented health systems in COVID-19: rectifying the misalignment between global health security and universal health coverage. The Lancet 2020.

54. Tromberg BJ, Schwetz TA, Pérez-Stable EJ, Hodes RJ, Woychik RP, Bright RA, Fleurence RL, Collins FS. Rapid scaling up of Covid-19 diagnostic testing in the United States-the NIH RADx initiative. N Engl J Med. 2020;383(11):1071-7.

55. Marwaha J, Halamka J, Brat G: Lifesaving ventilators will sit unused without a national data-sharing effort. 2020. 
56. Kidd MR. Five principles for pandemic preparedness: lessons from the Australian COVID-19 primary care response. In. British Journal of General Practice; 2020.

57. Hsu LY, Tan M-H: What Singapore can teach the US about responding to COVID-19. STAT News 2020.

58. Horton R. Offline: COVID-19 is not a pandemic. Lancet. 2020;396(10255):874.

59. Raisi-Estabragh Z, McCracken C, Bethell MS, Cooper J, Cooper C, Caulfield MJ, Munroe PB, Harvey NC, Petersen SE. Greater risk of severe COVID-19 in Black, Asian and Minority Ethnic populations is not explained by cardiometabolic, socioeconomic or behavioural factors, or by $25(\mathrm{OH})$-vitamin $\mathrm{D}$ status: study of 1326 cases from the UK Biobank. J Public Health. 2020;42(3):451-60.

60. Hamidianjahromi A. Why African Americans Are a Potential Target for COVID-19 Infection in the United States. Journal of Medical Internet Research. 2020;22(6):e19934-4.

61. Tangcharoensathien V, Bassett MT, Meng Q, Mills A: Are overwhelmed health systems an inevitable consequence of covid-19? Experiences from China, Thailand, and New York State. bmj 2021, 372.

62. Organization WH: COVID-19 health system response monitor, Thailand. 2020.

63. Narkvichien M: Thailand's 1 million village health volunteers-"unsung heroes"-are helping guard communities nationwide from COVID-19. Nonthaburi: World Health Organization 2020.

64. Kupferschmidt K, Cohen J. Can China's COVID-19 strategy work elsewhere? In. American Association for the Advancement of Science; 2020.

65. Al Saidi AMO, Nur FA, Al-Mandhari AS, El Rabbat M, Hafeez A, Abubakar A. Decisive leadership is a necessity in the COVID-19 response. The Lancet. 2020;396(10247):295-8.

66. Forman R, Atun R, McKee M, Mossialos $E$ : 12 Lessons learned from the management of the coronavirus pandemic. Health policy (Amsterdam, Netherlands) 2020.

67. Barberia LG, Gómez EJ. Political and institutional perils of Brazil's COVID-19 crisis. The Lancet. 2020;396(10248):367-8.

68. Ortega F, Orsini M. Governing COVID-19 without government in Brazil: Ignorance, neoliberal authoritarianism, and the collapse of public health leadership. Glob Public Health. 2020;15(9):125777.

69. Ezequiel GE, Jafet A, Hugo A, Pedro D, Ana Maria M, Carola OV, Sofia R, Odet S, Teresa T, Jorge H. The COVID-19 pandemic: a call to action for health systems in Latin America to strengthen quality of care. Int J Qual Health Care. 2021;33(1):mzaa062.

70. Rocha R, Atun R, Massuda A, Rache B, Spinola P, Nunes L, Lago M, Castro MC. Effect of socioeconomic inequalities and vulnerabilities on health-system preparedness and response to COVID-19 in Brazil: a comprehensive analysis. The Lancet Global Health 2021.

71. Lancet T. India under COVID-19 lockdown. Lancet. 2020;395(10233):1315.

72. Siddiqui AF, Wiederkehr M, Rozanova L, Flahault A. Situation of India in the COVID-19 pandemic: India's initial pandemic experience. Int J Environ Res Public Health. 2020;17(23):8994.

73. Taneja P, Bali AS. India's domestic and foreign policy responses to COVID-19. The Round Table 2021, 110(1):46-61. 
74. Choutagunta A, Manish G, Rajagopalan S. Battling COVID-19 with dysfunctional federalism: lessons from India. South Econ J. 2021;87(4):1267-99.

75. Mallapaty S. India's massive COVID surge puzzles scientists. Nature. 2021;592(7856):667-8.

76. Thiagarajan K. Why is India having a covid-19 surge? In. British Medical Journal Publishing Group; 2021.

77. Fisman DN, Greer AL, Tuite AR. Age Is Just a Number: A Critically Important Number for COVID-19 Case Fatality. Ann Intern Med. 2020;173(9):762-3.

78. Sudharsanan N, Didzun O, Bärnighausen T, Geldsetzer P. The contribution of the age distribution of cases to COVID-19 case fatality across countries: a 9-country demographic study. Annals of internal medicine 2020.

79. Think Global Health: The Myth of South Asian Exceptionalism. In: he Myth of South Asian Exceptionalism: South Asia's young population conceals the effects that COVID-19 has on its older and more vulnerable people. vol. 2020; 2020.

80. Ioannidis JP, Axfors C, Contopoulos-loannidis DG. Population-level COVID-19 mortality risk for nonelderly individuals overall and for non-elderly individuals without underlying diseases in pandemic epicenters. Environmental research. 2020;188:109890.

81. Kim D-H, Choe YJ, Jeong J-Y. Understanding and interpretation of case fatality rate of coronavirus disease 2019. Journal of Korean medical science 2020, 35(12).

82. Rajgor DD, Lee MH, Archuleta S, Bagdasarian N, Quek SC. The many estimates of the COVID-19 case fatality rate. Lancet Infect Dis. 2020;20(7):776-7.

83. Sorci G, Faivre B, Morand S. Explaining among-country variation in COVID-19 case fatality rate. Scientific reports. 2020;10(1):1-11.

84. Sen-Crowe B, Sutherland M, McKenney M, Elkbuli A. A closer look into global hospital beds capacity and resource shortages during the COVID-19 pandemic. journal of surgical research. 2021;260:5663.

85. Li M, Zhang Z, Cao W, Liu Y, Du B, Chen C, Liu Q, Uddin MN, Jiang S, Chen C. Identifying novel factors associated with COVID-19 transmission and fatality using the machine learning approach. Sci Total Environ. 2021;764:142810.

86. Undurraga EA, Chowell G, Mizumoto K: COVID-19 case fatality risk by age and gender in a high testing setting in Latin America: Chile, March-August 2020. Infectious diseases of poverty 2021, 10(1):1-11.

87. Taylor L: How Latin America is fighting covid-19, for better and worse. bmj 2020, 370.

88. Bhuyan A. Covid-19: India looks to import oxygen as cases surge, overwhelming hospitals. In.: British Medical Journal Publishing Group; 2021.

89. An BY, Tang S-Y. Lessons from COVID-19 responses in East Asia: Institutional infrastructure and enduring policy instruments. The American Review of Public Administration. 2020;50(6-7):790-800. 
90. Chen H, Shi L, Zhang Y, Wang X, Sun G. A cross-country core strategy comparison in China, Japan, Singapore and South Korea during the early COVID-19 pandemic. Globalization health. 2021;17(1):1-10.

91. Kahathuduwa CN, Dhanasekara CS, Chin S-H: Case fatality rate in COVID-19: a systematic review and meta-analysis. MedRXiV 2020.

92. Meyerowitz-Katz G, Merone L. A systematic review and meta-analysis of published research data on COVID-19 infection-fatality rates. International Journal of Infectious Diseases 2020.

93. Seoane B. A scaling approach to estimate the COVID-19 infection fatality ratio from incomplete data. arXiv preprint arXiv. 2006027572020.

94. Byambasuren O, Dobler CC, Bell K, Rojas DP, Clark J, McLaws M-L, Glasziou P. Comparison of seroprevalence of SARS-CoV-2 infections with cumulative and imputed COVID-19 cases: systematic review. PloS one. 2021;16(4):e0248946.

95. Shakiba M, Nazemipour M, Salari A, Mehrabian F, Nazari SSH, Rezvani SM, Ghasempour Z, Heidarzadeh A, Mansournia MA. Seroprevalence of SARS-CoV-2 in Guilan Province, Iran, April 2020. Emerg Infect Dis. 2021;27(2):636.

96. Chen Y-Y, Assefa Y. The heterogeneity of the COVID-19 pandemic and national responses: an explanatory mixed-methods study. BMC Public Health. 2021;21(1):1-15.

97. World Health Organization (WHO). Thirteenth general programme of work 2019-2023. The seventyfirst world health assembly Geneva (Switzerland): World Health Organization 2018.

98. Mahjour J, Mirza Z, Rashidian A, Atta H, Hajjeh R, Thieren M, El-Adawy M, Hammerich A, Al-Yousfi A, Haka RB. " Promote health, keep the world safe, serve the vulnerable" in the Eastern Mediterranean Region. Eastern Mediterranean Health Journal. 2018;24(4):323-4.

99. Paremoer L, Nandi S, Serag H, Baum F: Covid-19 pandemic and the social determinants of health. bmj 2021, 372.

100. Rawaf S, Allen LN, Stigler FL, Kringos D, Quezada Yamamoto H, van Weel C, Coverage GFoUH, Care $\mathrm{PH}$. Lessons on the COVID-19 pandemic, for and by primary care professionals worldwide. European Journal of General Practice. 2020;26(1):129-33.

101. Blanchet K, Alwan A, Antoine C, Cros MJ, Feroz F, Guracha TA, Haaland O, Hailu A, Hangoma P, Jamison D. Protecting essential health services in low-income and middle-income countries and humanitarian settings while responding to the COVID-19 pandemic. BMJ global health. 2020;5(10):e003675.

102. Thome J, Coogan AN, Fischer M, Tucha O, Faltraco F. Challenges for mental health services during the 2020 COVID-19 outbreak in Germany. Psychiatry and clinical neurosciences 2020.

103. Riley T, Sully E, Ahmed Z, Biddlecom A. Estimates of the potential impact of the COVID-19 pandemic on sexual and reproductive health in low-and middle-income countries. International Perspectives on Sexual Reproductive Health. 2020;46:73-6.

104. World Health Organization (WHO): Maintaining essential health services: operational guidance for the COVID-19 context: interim guidance, 1 June. 2020. In.: World Health Organization; 2020. 
105. World Health Organization (WHO): Pulse survey on continuity of essential health services during the COVID-19 pandemic: interim report, 27 August. 2020. In.: World Health Organization; 2020.

106. World Health Organization (WHO): Second round of the national pulse survey on continuity of essential health services during the COVID-19 pandemic: interim report, 22 April. 2021. In.: World Health Organization; 2021.

107. Organization WH. COVID-19: operational guidance for maintaining essential health services during an outbreak: interim guidance, 25 March 2020. In.: World Health Organization; 2020.

108. Nachega JB, Sam-Agudu NA, Masekela R, van der Zalm MM, Nsanzimana S, Condo J, Ntoumi F, Rabie $H$, Kruger M, Wiysonge CS. Addressing challenges to rolling out COVID-19 vaccines in African countries. The Lancet Global Health 2021.

109. Skegg D, Gluckman P, Boulton G, Hackmann H, Karim SSA, Piot P, Woopen C. Future scenarios for the COVID-19 pandemic. The Lancet. 2021;397(10276):777-8.

110. Nhamo G, Chikodzi D, Kunene HP, Mashula N. COVID-19 vaccines and treatments nationalism: Challenges for low-income countries and the attainment of the SDGs. Glob Public Health. 2021;16(3):319-39.

111. Figueroa JP, Bottazzi ME, Hotez P, Batista C, Ergonul O, Gilbert S, Gursel M, Hassanain M, Kim JH, Lall B. Urgent needs of low-income and middle-income countries for COVID-19 vaccines and therapeutics. The Lancet. 2021;397(10274):562-4.

112. Sanders D, Nandi S, Labonté R, Vance C, Van Damme W. From primary health care to universal health coverage-one step forward and two steps back. The Lancet. 2019;394(10199):619-21.

113. Hone T, Macinko J, Millett C: Revisiting Alma-Ata: what is the role of primary health care in achieving the Sustainable Development Goals? The Lancet 2018, 392(10156):1461-1472.

114. Redwood-Campbell L, Abrahams J. Primary health care and disasters-the current state of the literature: what we know, gaps and next steps. Prehospital Disaster Med. 2011;26(3):184-91.

115. Bitton A, Ratcliffe HL, Veillard JH, Kress DH, Barkley S, Kimball M, Secci F, Wong E, Basu L, Taylor C. Primary health care as a foundation for strengthening health systems in low-and middle-income countries. J Gen Intern Med. 2017;32(5):566-71.

116. Dunlop C, Howe A, Li D, Allen LN. The coronavirus outbreak: the central role of primary care in emergency preparedness and response. BJGP Open 2020, 4(1).

117. Assefa Y, Gilks CF, van de Pas R, Reid S, Gete DG, Van Damme W: Reimagining global health systems for the 21st century: lessons from the COVID-19 pandemic. BMJ global health 2021, 6(4):e004882.

118. Loewenson R, Accoe K, Bajpai N, Buse K, Abi Deivanayagam T, London L, Méndez CA, Mirzoev T, Nelson E, Parray AA. Reclaiming comprehensive public health. BMJ global health. 2020;5(9):e003886.

119. Gostin LO, Friedman EA. A retrospective and prospective analysis of the west African Ebola virus disease epidemic: robust national health systems at the foundation and an empowered WHO at the apex. The Lancet. 2015;385(9980):1902-9. 
Figures

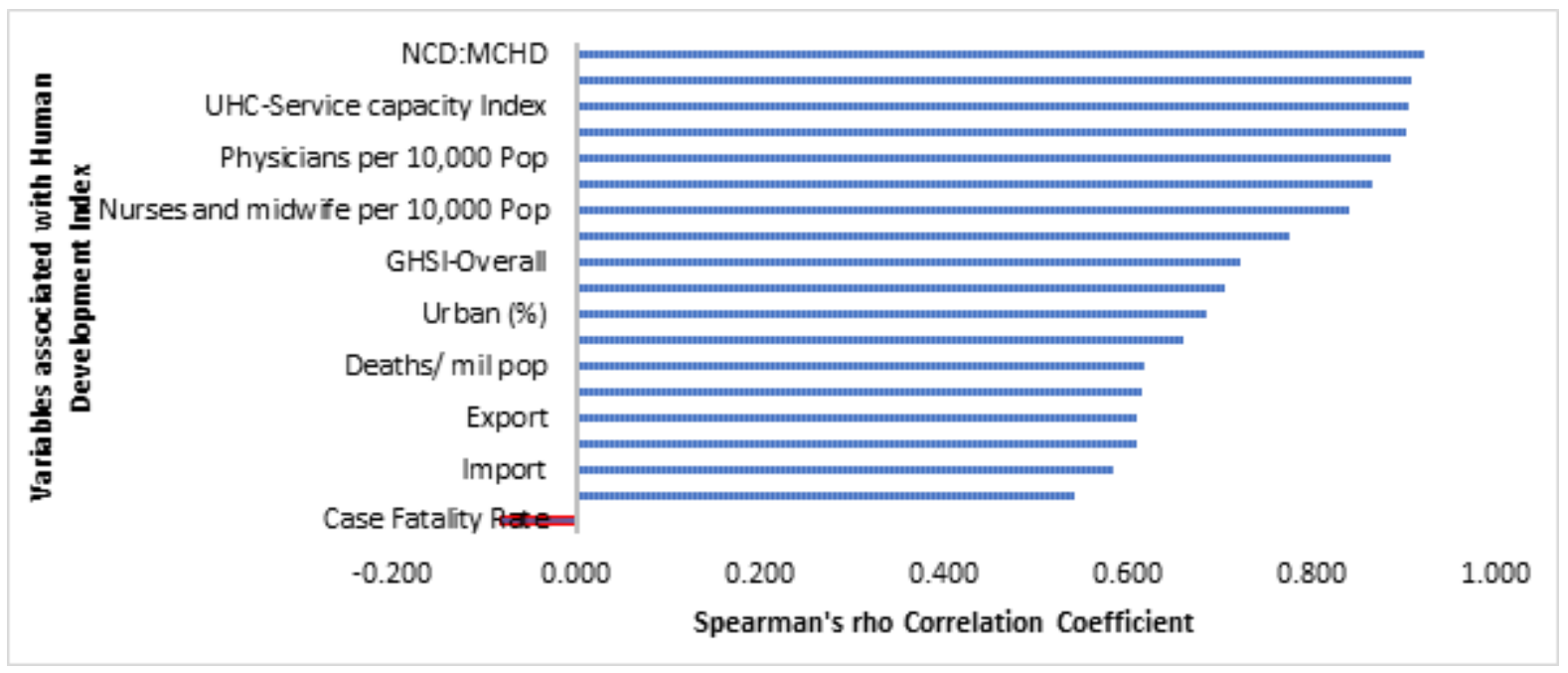

Figure 1

Human development index and its correlates associated with COVID-19 in 189 countries* *NCD: noncommunicable diseases; MCHD: maternal \& child health and infectious diseases; UHC: universal health coverage; GHSI: global health security index.

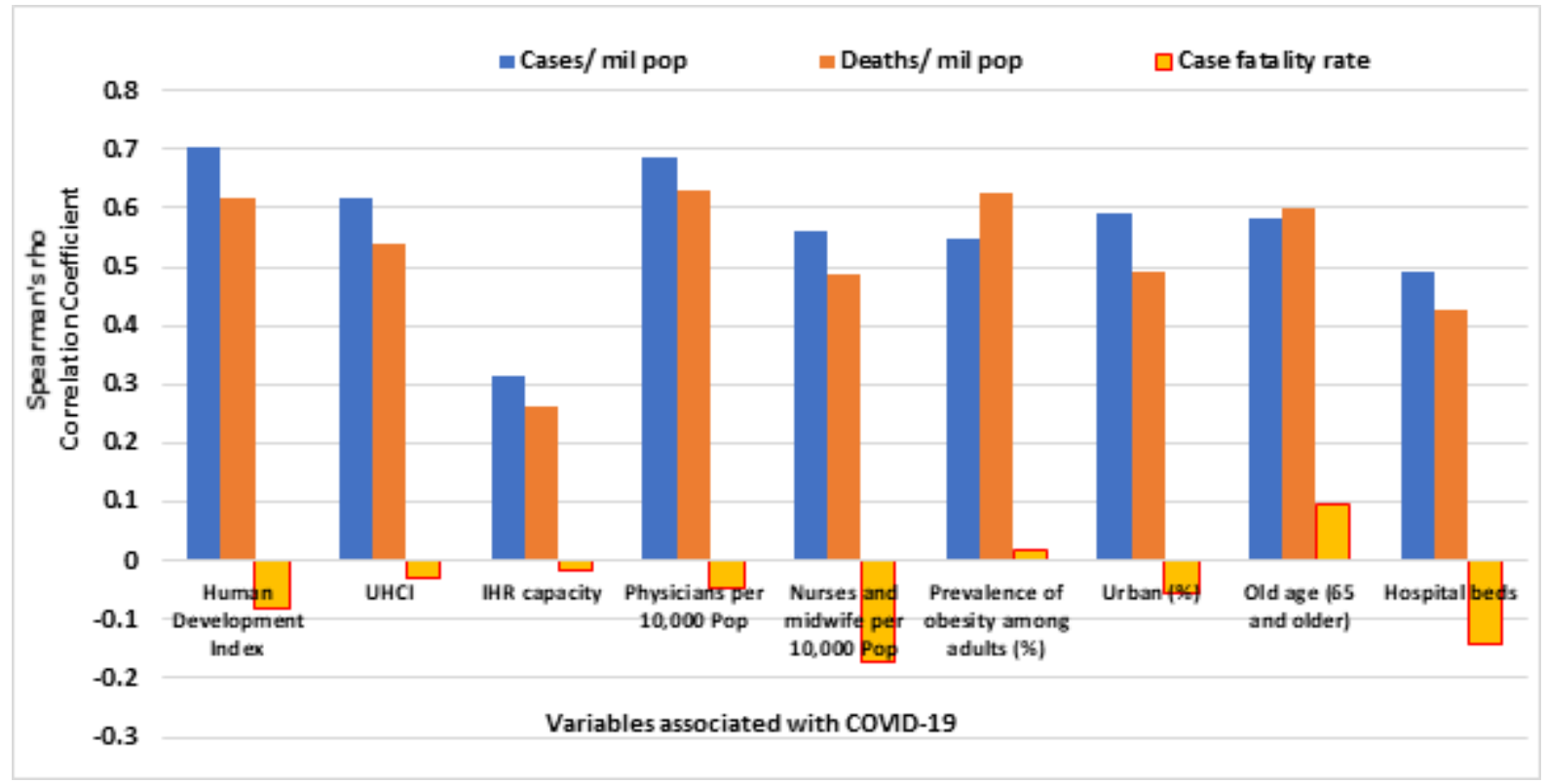

Figure 2

Correlates of COVID-19 cases, deaths and case-fatality rates in 189 countries 


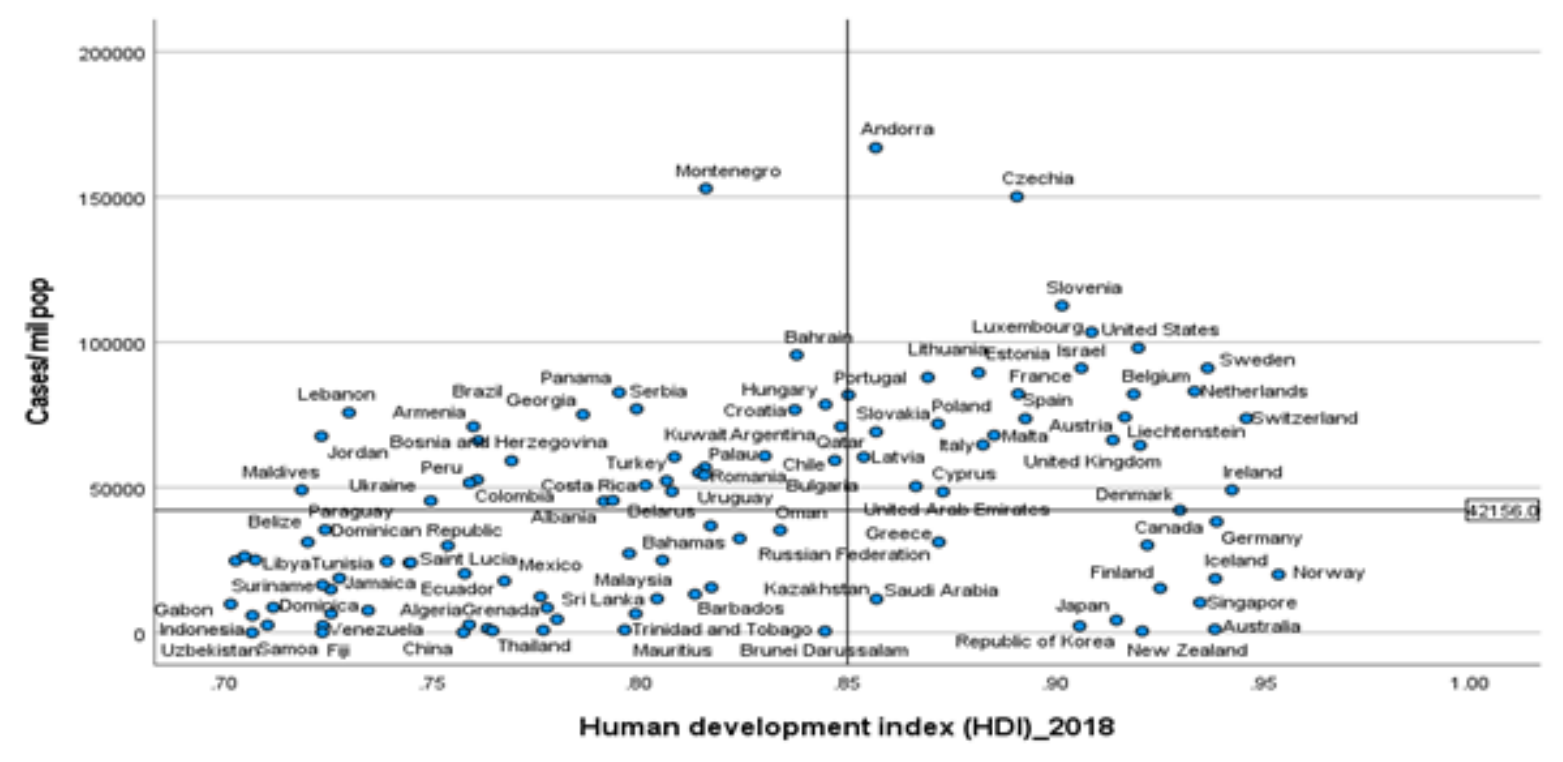

Figure 3

Scatter plot of COVID-19 cases per million population in countries with high human development index $(>0.70)$

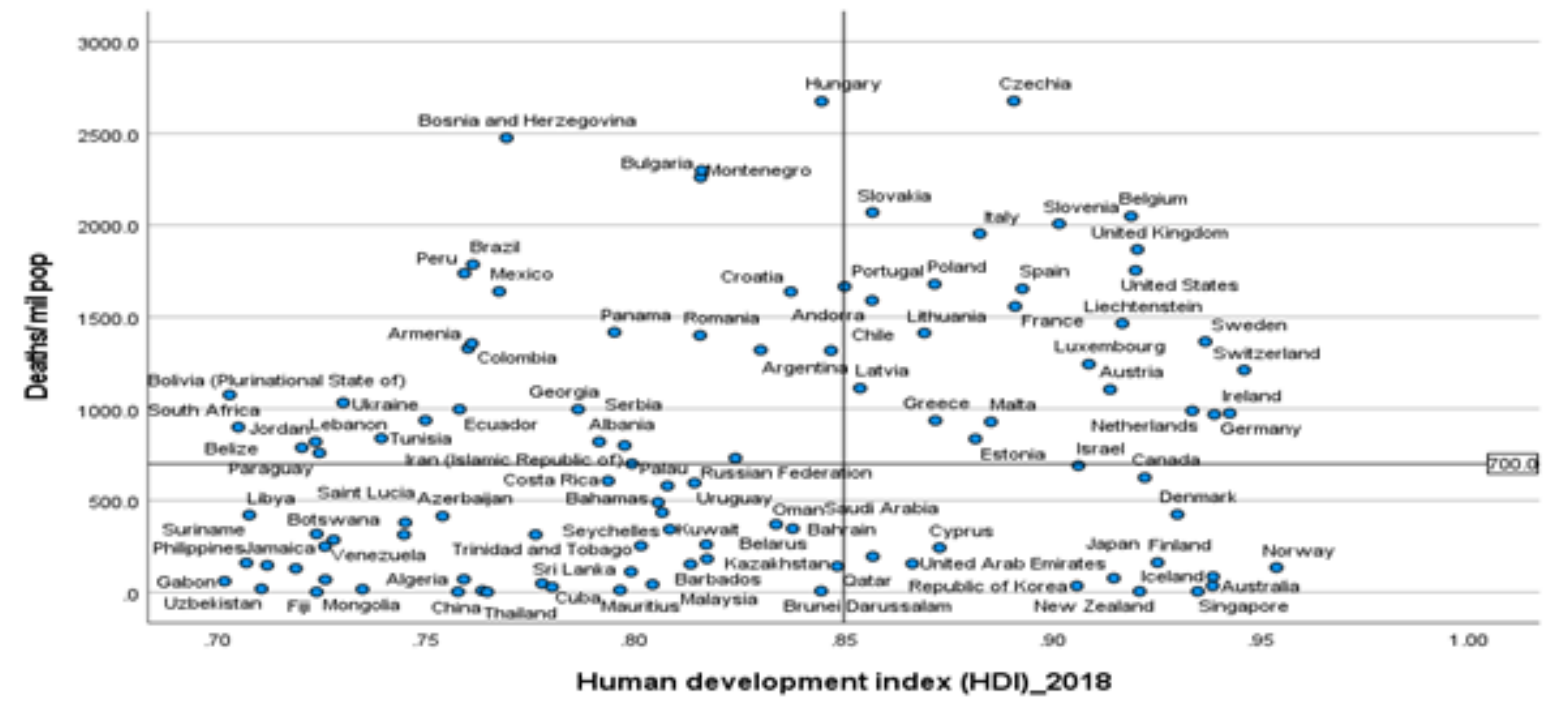

\section{Figure 4}

Scatter plot of COVID-19 deaths per million population in countries with high human development index $(>0.70)$ 